EXTENDED REPORT

\title{
Blood and synovial fluid cytokine signatures in patients with juvenile idiopathic arthritis: a cross-sectional study
}

\author{
Wilco de Jager, Esther P A H Hoppenreijs, Nico M Wulffraat, Lucy R Wedderburn, Wietse Kuis, \\ Berent J Prakken
}

See end of article for authors' affiliations

Correspondence to:

Professor B J Prakken

Department of Pediatric

Immunology (KCO10690),

University Medical Center

Utrecht, Lundlaan 6, 3584

EA Utrecht, The Netherlands;

bprakken@umcutrecht.nl

Accepted 2 December 2006

Published Online First

14 December 2006

Background: Juvenile idiopathic arthritis (JIA) consists of a heterogeneous group of disorders with, for the most part, an unknown immunopathogenesis. Although onset and disease course differ, the subtypes of JIA share the occurrence of chronic inflammation of the joints, with infiltrations of immunocompetent cells that secrete inflammatory mediators.

Objective: To identify a panel of cytokines specifically related to the inflammatory process in JIA.

Methods: Using a new technology, the multiplex immunoassay, 30 cytokines were measured in plasma of 65 patients with JIA, of which 34 were paired with synovial fluid. These data were compared with plasma of 20 healthy controls and 9 patients with type I diabetes, a chronic inflammatory disease.

Results: Patients with JIA had, irrespective of their subclassification, significantly higher levels of tumour necrosis factor $\alpha$, macrophage inhibitory factor (MIF), CCL2, CCL3, CCL1 1, CCL22 and CXCL9 in plasma than controls. In paired plasma and synovial fluid samples of patients with JIA, significantly higher levels of interleukin (IL)6, IL15, CCL2, CCL3, CXCL8, CXCL9 and CXCL10 were present in synovial fluid. Cluster analysis in all patients with JIA revealed a predominant pro-inflammatory cytokine cluster during active disease and a regulatory/anti-inflammatory-related cytokine cluster during remission. Whether a discrimination profile of various cytokines could help in the determination of disease classification was tested. Conclusion: It is suggested that several cytokines (IL18, MIF, CCL2, CCL3, CCL1 1, CXCL9 and CXCL10) may correspond to the activation status during inflammation in JIA and could be instrumental in monitoring disease activity and outcomes of (new) immunotherapies.

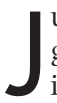
uvenile idiopathic arthritis (JIA) consists of a heterogeneous group of disorders with unknown aetiology. This autoimmune disorder is a major cause of chronic disability in children. The underlying factors influencing susceptibility are thought to include a combination of environmental interactions and genes. ${ }^{1}$ Although onset and disease course may differ, the subtypes of JIA share the occurrence of chronic inflammation of the joints. Monocytes, macrophages, fibroblasts and T cells within the inflamed microenvironment secrete many mediators that interact directly with the surrounding tissue and tend to have a pro-inflammatory character. ${ }^{2}{ }^{3}$ The produced interleukins (ILs) regulate the production of inflammatory mediators from the surrounding tissue, whereas secreted chemotactic cytokines (chemokines) function as regulatory molecules that attract and direct the differentiation of new potent inflammatory cells to the site of inflammation. ${ }^{4-7}$

Cytokine profiles in both plasma and synovial fluid are no more than a reflection of the local inflammatory process. However, detection of these mediators might serve as biomarkers for disease diagnosis, prognosis and treatment outcome. Indeed, analysis of individual mediators with ELISA and mRNA detection has contributed to our understanding of the immune and inflammatory reactions in JIA. Increased levels of pro-inflammatory cytokines and decreased production of the regulatory cytokine IL10 have been reported as biomarkers for disease. ${ }^{8-12}$ Through the characterisation of cytokine pathways, new treatments have been developed using monoclonal antibodies that block specific components of the immune system, and, consequently, modulate the inflammatory process. An immune intervention based on blocking the biological effects of tumour necrosis factor (TNF) $\alpha$ and ILl is effective for the treatment of JIA, whereas an antibody that blocks IL6 as well as several chemokine-based interventions are under investigation. ${ }^{13-19}$
Owing to systemic intervention of the immune system, major changes will occur in the cytokine milieu downstream of these pro-inflammatory pathways. Circulating cytokines correspond to the activation status of immunocompetent cells, and it could be instrumental to monitor changes in this profile during treatment. Intervention with monoclonal antibodies is not without risk, as illustrated by the occurrence of serious side effects such as drug-induced autoimmunity by accumulation of cytokines (interferon (IFN) $\alpha$ ) in blood after anti-TNF $\alpha$ treatment, ${ }^{2021}$ as well as the dramatic side effects observed in healthy volunteers after administration of a monoclonal antibody directed against CD28. ${ }^{22}{ }^{23}$ These severe side effects after administration of this antibody are partly due to an evolving cytokine storm. ${ }^{24}$ Evaluating circulating cytokines and chemokines in plasma might help in identifying surrogate parameters for disease activity, disease severity, risk of side effects and treatment outcome.

Innovation in the technology for detection of proteins has led to the development of particle-based multiplex immunoassays (MIAs). This new technology allows individual and multiplex analysis of up to a hundred different mediators in a single sample volume of $50 \mu \mathrm{l}^{25-27}$ We have developed an MIA to detect 30 human soluble mediators, all related to chronic inflammation, in plasma and in synovial fluid. ${ }^{27}$ Using this technology, we measured a panel of ILs, chemokines and soluble adhesion molecule profiles in plasma and synovial fluid of patients with oligoarticular, polyarticular and systemic JIA as

Abbreviations: $C R P, C$ reactive protein; $E S R$, erythrocyte sedimentation rate; IFN, interferon; IL, interleukin; JIA, juvenile idiopathic arthritis; MIA, multiplex immunoassay; MIF, macrophage inhibitory factor; NK, natural killer; OSM, oncostatin $M$; RANKL, receptor activator of nuclear factor $\kappa B$ ligand; Th, T helper (cell); TNF, tumour necrosis factor 
Table 1 Clinical characteristics of the patient populations

\begin{tabular}{|c|c|c|c|c|c|c|c|}
\hline & \multicolumn{2}{|l|}{ Oligoarticular } & \multicolumn{2}{|l|}{ Polyarticular } & \multicolumn{2}{|l|}{ Systemic } & \multirow{2}{*}{$\begin{array}{l}\text { Diabetes } \\
\text { Plasma } \\
(\mathrm{n}=9)\end{array}$} \\
\hline & $\begin{array}{l}\text { Plasma } \\
(\mathrm{n}=30)\end{array}$ & $\begin{array}{l}\text { Synovial fluid } \\
(n=19)\end{array}$ & $\begin{array}{l}\text { Plasma } \\
(n=15)\end{array}$ & $\begin{array}{l}\text { Synovial fluid } \\
(n=6)\end{array}$ & $\begin{array}{l}\text { Plasma } \\
(\mathrm{n}=20)\end{array}$ & $\begin{array}{l}\text { Synovial fluid } \\
(n=9)\end{array}$ & \\
\hline Female/male & $21 / 9$ & $16 / 3$ & $8 / 7$ & $7 / 2$ & $13 / 7$ & $4 / 2$ & $4 / 5$ \\
\hline Age (range; years) & $9.9(3.0-15.1)$ & $9.2(2.1-17.0)$ & $10.7(3.6-17.5)$ & $10.1(3.8-17.3)$ & $19.5(2.3-14.8)$ & $10.6(7.7-13.4)$ & $10.4(4.7-13.9)$ \\
\hline $\begin{array}{l}\text { Disease duration } \\
\text { (range; years) }\end{array}$ & $5.9(0.4-14.0)$ & $4.7(0.4-14.0$ & $2.7(0.3-7.0)$ & $4.4(0.8-8.5)$ & $4.7(0.2-11.0)$ & $5.9(12.1-10.0)$ & $6.8(1.2-12.1)$ \\
\hline $\begin{array}{l}\text { Active/non-active } \\
\text { disease }\end{array}$ & $20 / 10$ & 19 & $8 / 7$ & 9 & $13 / 7$ & 6 & \\
\hline $\mathrm{ESR}(\mathrm{mm} / \mathrm{h})$ & $13.2(2-55)$ & $31.2(7-104)$ & $46.7(5-171)$ & $43.0(7-80)$ & $13.9(5-47)$ & $63.1(7-171)$ & ND \\
\hline CRP (range; mg/l) & $22.9(<1-90)$ & $34.1(3-90)$ & $45.0(2-111)$ & 35.2 (15-95) & $29.5(3-110)$ & $33.0(18-70)$ & ND \\
\hline ANA positive* & $7(23 \%)$ & $13(68 \%)$ & $2(13 \%)$ & $2(22 \%)$ & $8(40 \%)$ & $0(0 \%)$ & ND \\
\hline RF positive & $0(0 \%)$ & $0(0 \%)$ & $0(0 \%)$ & $1(11 \%)$ & $3(15 \%)$ & $0(0 \%)$ & ND \\
\hline NSAID & $24(80 \%)$ & $18(95 \%)$ & $14(93 \%)$ & $8(89 \%)$ & $19(95 \%)$ & $6(100 \%)$ & $0(0 \%)$ \\
\hline MTX & $12(40 \%)$ & $8(42 \%)$ & $8(53 \%)$ & $7(78 \%)$ & $11(55 \%)$ & $5(83 \%)$ & $0(0 \%)$ \\
\hline Corticosteroids & $1(3 \%)$ & $1(5 \%)$ & $4(27 \%)$ & $2(22 \%)$ & $2(10 \%)$ & $4(67 \%)$ & $0(0 \%)$ \\
\hline Anti-TNF $\alpha$ & $0(0 \%)$ & $0(0 \%)$ & $2(13 \%)$ & $1(11 \%)$ & $3(15 \%)$ & $2(33 \%)$ & $0(0 \%)$ \\
\hline
\end{tabular}

ANA, antinuclear antibody; CRP, C reactive protein; ESR, erythrocyte sedimentation rate; NSAID, non-steroidal anti-inflammatory drug; MTX, methotrexate; RF, rheumatoid factor; $\mathrm{TNF} \alpha$, tumour necrosis factor $\alpha$.

*Determined by indirect immunofluorescence on Hep-2 cells.

†Determined by IgM ELISA.

well as in plasma of healthy controls. We correlated plasma cytokine levels with disease activity and used a mathematical approach to assess the predictive value of cytokines and chemokines for the diagnosis of JIA.

\section{MATERIALS AND METHODS \\ Participants}

All children in this cross-sectional study were classified according to the International League Against Rheumatism criteria $^{28}{ }^{29}$ and divided into three major subgroups: (persistent) oligoarticular JIA, polyarticular JIA (including five extended oligoarticular JIA) and systemic JIA. Blood samples of 30 patients with oligoarticular JIA, 20 patients with polyarticular JIA and 15 patients with systemic JIA, 20 sex- and age-matched controls, and 9 patients with type I diabetes were obtained at either the outpatient clinic of the University Medical Center Utrecht, Utrecht, The Netherlands or Great Ormond Street Hospital for Children, London, UK. The study had full ethical approval at both centres. Patients with extended oligoarthritis ( $>4$ joints affected after 6 months of arthritis, at the time of venepuncture) were included in the polyarticular JIA subgroup. Furthermore, synovial fluid samples were obtained at the time of a therapeutic joint aspiration from 19 patients with oligoarticular JIA, 9 patients with polyarticular JIA and 6 patients with systemic JIA at both centres. Synovial fluid was collected in sodium heparin tubes and prepared in the same manner as the blood samples. Blood and synovial fluid were centrifuged to remove cells. Cell-free plasma and synovial fluid samples were stored frozen at $-80^{\circ} \mathrm{C}$ until analysis. Table 1 shows the general characteristics of the patients.

Active disease was defined by the presence of joint swelling or limitation of movement with either pain on movement or tenderness. Non-active disease (remission) was defined by the absence of joint swelling or limitation of movement with either pain on movement or tenderness. ${ }^{30}$ Fever and laboratory evaluation of C-reactive protein (CRP) and erythrocyte sedimentation rate (ESR) levels were used as additional parameters for disease activity in systemic JIA. Informed consent was obtained either from parents or from the individuals directly if they were $\geqslant 12$ years.

Before each assay, all samples were centrifuged in a polypropylene centrifuge tube containing a $0.22 \mu \mathrm{m}$ nylon membrane (Spin-X Column; Corning, Corning, New York, USA) to remove debris. Furthermore, the viscosity of the synovial fluid samples was reduced by treatment with hyaluronidase (type IV-S, Sigma-Aldrich, St Louis, Missouri, USA) at a concentration of $20 \mathrm{U} / \mathrm{ml}$ for $30 \mathrm{~min}$ at $37^{\circ} \mathrm{C}$, followed by centrifugation.

\section{Multiplex immunoassay}

All 30 antibody pairs and recombinant proteins used were purchased from commercial sources as described previously. ${ }^{27}$ Thirty different carboxylated polystyrene microspheres were purchased from Luminex Corporation (Austin, Texas, USA). The capture antibodies were covalently coupled to the microspheres as described previously. ${ }^{25} 27$

Non-specific heterophilic immunoglobulins such as rheumatoid factor were pre-absorbed from all samples with protein-L (Pierce, Rockford, Illinois, USA) as described earlier. ${ }^{27}$ To block any residual of interfering antibodies, the samples were diluted with $10 \% \mathrm{v} / \mathrm{v}$ normal rat and mouse serum (1:1 ratio; Rockland, Gilbertsville, Pennsylvania, USA). Samples were run undiluted and diluted 1:50 in high-performance ELISA buffer (Sanquin, Amsterdam, The Netherlands).

Calibration curves from recombinant protein standards were prepared using twofold dilution steps in serum diluent (R\&D Systems, Abingdon, UK) as described previously. ${ }^{27}$ Samples were measured and blank values were subtracted from all readings. All assays were carried out directly in a 96-well $1.2 \mu \mathrm{m}$ filter plate (Millipore, Billerica, Massachusetts, USA) at room temperature and protected from light. A mixture containing 1000 microspheres per mediator (total volume $10 \mu \mathrm{l} /$ well) was incubated together with a standard, sample or blank for $\mathrm{l} \mathrm{h}$ at room temperature. Next, $10 \mu \mathrm{l}$ of a cocktail of biotinylated antibodies $(16.5 \mu \mathrm{g} / \mathrm{ml}$ each) was added to each well and incubated for an additional $60 \mathrm{~min}$. Beads were then washed with phosphate-buffered saline supplemented with $1 \%$ bovine serum albumin and $0.5 \%$ Tween 20 at pH 7.4, after incubating for $10 \mathrm{~min}$ with $50 \mathrm{ng} /$ well streptavidin R-phycoerythrin (BD Biosciences, San Diego, California, USA) and washing twice with phosphate-buffered saline, 1\% bovine serum albumin and $0.5 \%$ Tween 20 at $\mathrm{pH}$ 7.4. Fluorescence intensity of the beads was measured in a final volume of $100 \mu \mathrm{l}$ high-performance ELISA buffer. Measurements and data analysis of all assays were performed using the Bio-Plex system in combination with the Bio-Plex Manager software V.4.0 using five parametric curve fitting (Bio-Rad Laboratories, Hercules, California, USA). 
Table 2 Cytokine and chemokines levels in plasma of healthy controls, and in patients with juvenile idiopathic arthritis and diabetes

\begin{tabular}{|c|c|c|c|c|c|c|c|c|}
\hline \multirow[b]{2}{*}{ Mediator } & \multirow[b]{2}{*}{ Controls } & \multicolumn{2}{|c|}{ Oligoarticular JIA } & \multicolumn{2}{|c|}{ Polyarticular JIA } & \multicolumn{2}{|l|}{ Systemic JIA } & \multirow[b]{2}{*}{ Diabetes } \\
\hline & & Remission & Active & Remission & Active & Remission & Active & \\
\hline $\operatorname{IL} 1 \alpha$ & $0.1(0.0)$ & $0.3(0.3)$ & $15(7.5)$ & $0.3(0.2)$ & $22(21)$ & $1.1(0.9)$ & $0.3(0.2)$ & $0.9(1.6)$ \\
\hline IL1 $\beta$ & $1.2(0.6)$ & $9.9(8.7)$ & $16(6.3)$ & $2.5(1.6)$ & $50(38)$ & $0.7(0.6)$ & $2.5(1.3)$ & $2.3(13)$ \\
\hline IL2 & $0.1(0.1)$ & $0.1(0.1)$ & $3.8(2.3)$ & $0.2(0.2)$ & $4.2(3.9)$ & $0.1(0.1)$ & $0.2(0.1)$ & $0.1(0.7)$ \\
\hline IL4 & $0.0(0.0)$ & $0.2(0.1)$ & $4.6(1.9)$ & $0.1(0.1)$ & 18 (17) & $0.0(0.0)$ & $1.1(1.1)$ & $0.1(0.1)$ \\
\hline IL5 & $0.0(0.0)$ & $0.3(0.3)$ & $2.4(1.0)$ & $1.0(0.6)$ & $32(31)$ & $0.0(0.0)$ & $0.1(0.1)$ & $1.8(2.0)$ \\
\hline IL6 & $6(7.6)$ & $116(101)$ & $563(405)^{*}, \dagger$ & $16(7.0)$ & $378(236) \ddagger$ & $7.2(5.9)$ & $29(13) \dagger$ & $22(38)$ \\
\hline IL10 & $0.3(0.3)$ & $1.1(1.0)$ & $6.3(2.2)$ & $0.7(0.4)$ & $50(48)$ & $0.5(0.4)$ & $3.7(2.4)$ & $1.2(1.5)$ \\
\hline IL12 & $7.5(2.4)$ & $6.6(4.1)$ & $19(4.2) \dagger$ & 15 (12) & $20(9.1) \dagger$ & $4.3(3.1)$ & $49(22) \ddagger$ & $16(4.5)$ \\
\hline IL13 & $1.9(1.6)$ & $3.4(3.1)$ & $17(7.4)$ & $1.3(1.0)$ & $48(30)$ & $0.3(0.2)$ & $3.6(7.4)$ & $0.9(2.1)$ \\
\hline IL15 & $0.0(0.0)$ & $0.0(0.0)$ & $0.5(0.3)$ & $0.2(0.2)$ & $2.2(2.2)$ & $0.2(0.1)$ & $0.5(1.5)$ & $0.3(0.6)$ \\
\hline IL17 & $0.3(0.2)$ & $0.0(0.1)$ & $425(241) \S$ & $0.0(0.0)$ & $100(94)^{*}$ & $1.3(1.0)$ & $0.0(0.1)$ & $0.3(4.7)$ \\
\hline IL18 & $133(29)$ & $153(51)$ & $172(24)$ & $205(268)$ & $194(60)$ & $770(246) \S$ & $5622(1348) \S$, & 108 (71) \\
\hline $\mathrm{TNF} \alpha$ & $1.1(0.6)$ & $4.0(3.6)$ & $15(6.3)$ & $4.1(2.1)$ & 20 (17) & $0.4(0.3)$ & $2.9(8.2)$ & $1.6(6.2)$ \\
\hline $\mathrm{IFN} \gamma$ & 55 (104) & $102(594)$ & $201(100)$ & 89 (39) & $534(242)$ & $54(34)$ & $101(286)$ & 70 (274) \\
\hline OSM & $1.6(0.4)$ & $1.9(1.2)$ & $328(231)$ & $4.4(3.2)$ & $18(12)$ & $1.8(0.5)$ & $2.8(0.9)$ & $0.1(0.4)$ \\
\hline$M I F * \star$ & $2.3(0.4)$ & 7.4 (2.3)t† & $6.6(1.1)$ & $7.6(1.8)+\dagger$ & 30 (10)§ & $6.2(6.9) \mathrm{t \dagger}$ & 15 (3.4)†† & $3.7(5.6)$ \\
\hline CCL2 & $20(10)$ & $38(10)$ & $80(18)$ & 34 (12) & 50 (17) & $24(10)$ & $8.8(1.9)$ & 69 (39)tt \\
\hline CCL3 & $56(15)$ & 85 (39) & $1416(378) \S$, & $440(225)$ & $1099(749) \S, \dagger$ & $126(45)$ & $881(358) \S, \dagger$ & $168(31)$ \\
\hline $\mathrm{CCL}^{\star *}$ & $63(0.4)$ & $63(7.5)$ & $142(38)$ & $56(12)$ & 85 (13) & $61(9.2)$ & 74 (11) & 49 (14) \\
\hline CCL11 & $10(2.9)$ & $55(26)$ & $80(24)$ & $60(24)$ & 44 (16) & $26(13)$ & $6.3(2.5)$ & 15 (14) \\
\hline CCL17 & $44(24)$ & 109 (47) & $107(23)$ & $33(8.8)$ & 65 (16) & 97 (31) & $44(24)$ & 61 (46) \\
\hline CCL18** & $40(5.2)$ & $24(5.0)$ & $49(15.2)$ & $35(6.6)$ & $47(23)$ & $29(8.5)$ & $42(8.7)$ & 36 (11) \\
\hline CCL22 & $389(52)$ & 1378 (1009) & $1703(385)$ & 483 (129) & $1430(758)$ & 452 (112) & 1264 (911) & 233 (139) \\
\hline CXCL8 & $0.2(0.1)$ & $284(263)$ & $287(249)$ & $23(15)$ & 71 (44) & $0.1(0.5)$ & $2.4(1.9)$ & $104(36)^{*}$ \\
\hline CXCL9 & $8.4(3.0)$ & 34 (29) & $127(54)^{*}$,†† & $22(11)$ & $102(50)^{*}$, †† & $1.8(0.9)$ & $41(24) \dagger \dagger, \dagger$ & $6.3(10)$ \\
\hline CXCL10 & $98(36)$ & $171(65)$ & $828(216) \S, \dagger$ & 289 (119) & $442(130)^{*}$, & 70 (29) & $137(45)+\uparrow, \dagger$ & 242 (105)†† \\
\hline OPG** & $0.7(0.5)$ & $0.8(0.5)$ & $5.9(2.6)$ & $0.4(0.2)$ & $2.4(1.6)$ & $1.7(0.5) \mathrm{t \dagger}$ & $2.8(2.2)$ & $2.4(1.5)$ \\
\hline sRANKL & $0.9(0.4)$ & $0.3(0.1)$ & $3.2(2.8)$ & $1.5(0.9)$ & $30(28)$ & $3.9(3.4)$ & $1.2(0.7)$ & 0.8 (1.3) \\
\hline sCD54** & $159(5.9)$ & $145(10)$ & $158(24)$ & $185(134)$ & $173(24)$ & $161(14)$ & $228(44)$ & $131(27)$ \\
\hline sCD106** & $566(31)$ & 776 (177) & 739 (63) & 733 (63) & 984 (299) & $656(58)$ & 723 (104) & 542 (91) \\
\hline
\end{tabular}

IFN, interferon; IL, interleukin; JIA, juvenile idiopathic arthritis; MIF, macrophage inhibitory factor; ND, not done; OPG, osteoprotergerin; OSM, oncostatin M; sRANKL, soluble receptor activator of nuclear factor- $\kappa$ B ligand; TNF, tumour necrosis factor.

*All values (mean (SD)) are expressed in $\mathrm{pg} / \mathrm{ml}$ (except for those marked **which are expressed in $\mathrm{ng} / \mathrm{ml}$ ).

tSignificant difference between controls and patients; $p<0.01$.

$¥$ Significant difference between disease activity of one specified subtype of JIA compared with all other patients with JIA; $p<0.05$.

- Significant difference between disease activity of one specified subtype of JIA compared with all other patients with JIA; $p<0.01$.

$\S$ Significant difference between disease activity of one specified subtype of JIA compared with all other patients with JIA; $p<0.001$.

${ }^{*}$ Significant difference between controls and patients; $p<0.001$.

$\dagger+$ Significant difference between controls and patients; $p<0.05$.

\section{Data analysis}

Basic descriptive statistics were used to describe the patient population. The differences in cytokine levels between different subgroups of JIA and controls, as well as correlations between soluble mediators and disease activity, were assessed using bivariate logistic regression. Differences in both CRP and ESR levels were determined by Student's t test. A p value $<0.05$ was considered significant. Owing to large biological variability in cytokine levels and non-Gaussian distribution, geometric means were used to generate colour profile figures. To investigate whether a single cytokine or chemokine or a combination of multiple cytokines and chemokines contribute to disease sub-classification and disease status, a cluster analysis was performed. All statistical analyses were performed using SPSS software V.12.0.1.

\section{RESULTS}

\section{Cytokine signature in plasma}

\section{Controls versus JIA}

Plasma concentrations of all mediators were measured in a cross-sectional study of 65 children with JIA, 20 age- and sexmatched controls, as well as 9 patients with inflammatory disease (diabetes). Although cytokine levels varied throughout the whole population, no detectable or very low levels $(<10 \mathrm{pg} /$ $\mathrm{ml}$ ) of ILs were present in plasma of controls except for IL6, IL18 and IFN $\gamma$ (table 2). Most chemokines were expressed constitutively at detectable levels in plasma of controls.
Patients with JIA had a completely different signature of cytokine expression in plasma compared with controls and patients with diabetes. Comparing all patients with JIA with controls without stratifying for disease activity or JIA subtype showed significantly higher expression in plasma of TNF $\alpha$ $(p<0.05)$, CCL3 (macrophage inflammatory protein $1 \alpha$, $\mathrm{p}<0.05$ ), CCL22 (macrophage-derived chemokine, $p<0.05$ ), CXCL9 (monokine induced by IFN $\gamma, \mathrm{p}<0.05$ ), macrophage inhibitory factor (MIF, $\mathrm{p}<0.01)$, CCL2 (monocyte chemoattractant protein-1, $\mathrm{p}<0.01$ ), and CCLll (eotaxin, $\mathrm{p}<0.01$ ), whereas CXCL10 (IFN $\gamma$ inducible protein 10) showed a trend towards significance $(\mathrm{p}=0.053$; fig 1$)$. When patients with diabetes were compared with controls, significantly higher levels of CCL2 $(\mathrm{p}<0.05)$, CXCL8 $(\mathrm{p}<0.01)$ and CXCL10 $(\mathrm{p}<0.05)$ were found in plasma (table 2$)$.

\section{JIA, active and non-active disease}

Next, the cytokine signatures in plasma of each JIA subtype were compared with disease activity at the time when blood was drawn. During remission, no significant differences were found in plasma of children of the various groups of JIA compared with controls except for significantly increased levels of IL18 and osteoprotergerin in patients with systemic JIA and MIF in all patients (table 2). It has to be noted that, although not significant because of the large distribution even within the population of patients with oligoarticular JIA during (drug-free) remission, increased pro-inflammatory cytokines, 

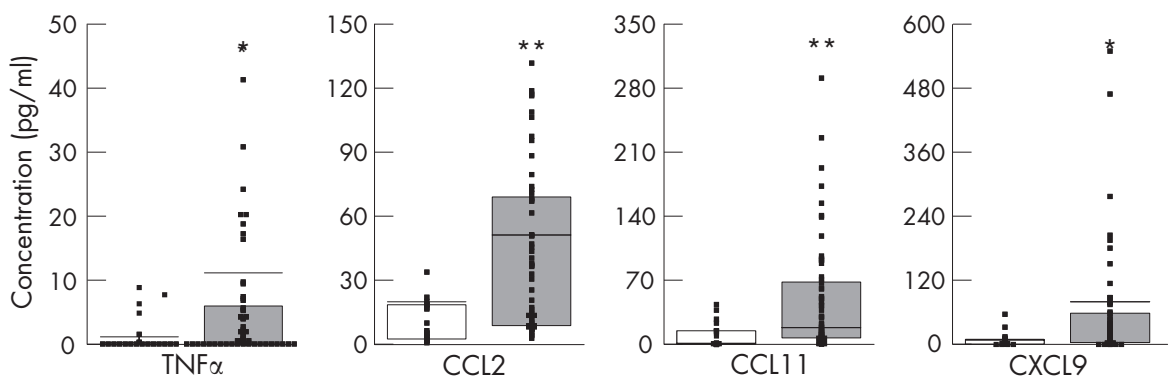

Figure 1 Cytokine and chemokine concentrations in plasma of healthy controls and patients with juvenile idiopathic arthritis (JIA). Box and whisker plots with median plasma concentrations from a cross-sectional study of controls (blank bars) and patients with JIA (grey bars). The results of each individual are depicted and only for those mediators that differed significantly between patients with JIA and controls. ${ }^{*} p<0.05$, ${ }^{* *} \mathrm{p}<0.01$. MIF, macrophage inhibitory factor; TNF, tumour necrosis factor.
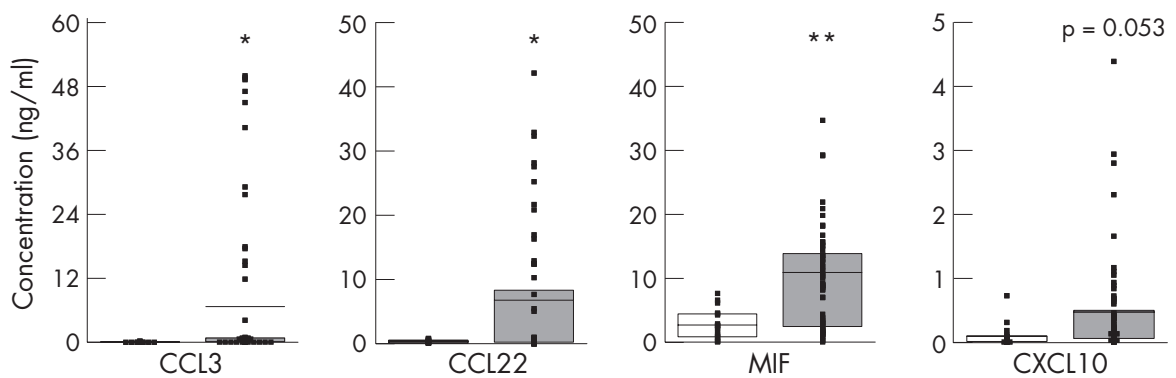

such as IL6, IFN $\gamma$ and CXCL8 (IL8), were often present in plasma, suggestive of an ongoing subclinical inflammatory

During active disease, as expected, the picture is totally process.

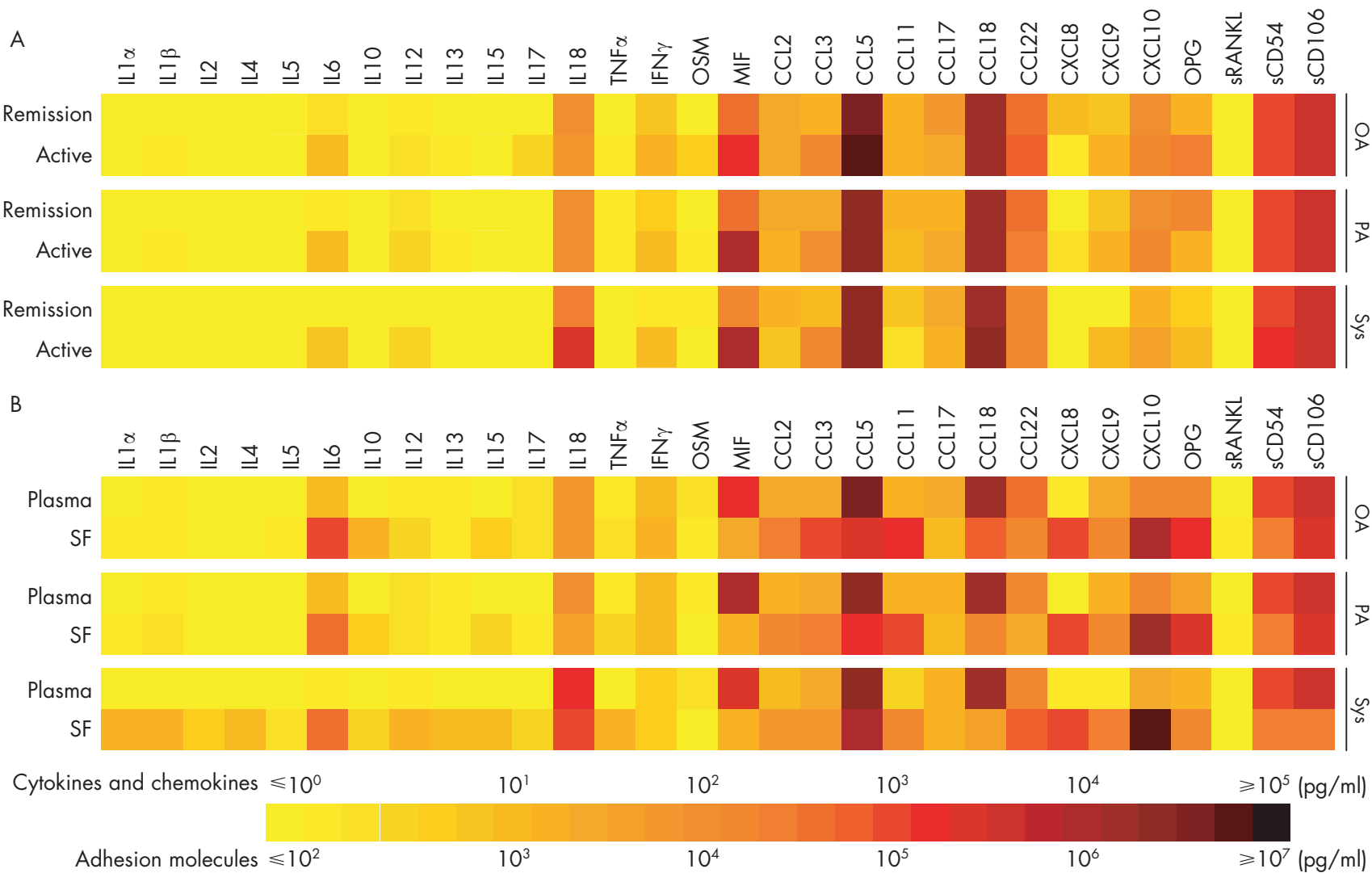

Figure 2 Cytokine, chemokine and soluble adhesion molecule profiles in plasma and synovial fluid (SF) of patients with juvenile idiopathic arthritis (JIA). Using a multiplex immunoassay, levels of cytokines, chemokines and soluble adhesion molecules $(\mathrm{pg} / \mathrm{ml})$ were measured in plasma and SF of patients with JIA. A colour profile of the geometric means was made to show differences between active and remission disease of each individual patient group (A) and differences during active disease between plasma and SF (B). IFN, interferon; IL, interleukin; MIF, macrophage inhibitory factor; OA, oligoarticular JIA; OPG, osteoprotergerin; OSM, oncostatin M; PA, polyarticular JIA; sRANKL, soluble receptor activator of nuclear factor $\kappa \mathrm{B}$ ligand; $S F$, synovial fluid; Sys, systemic JIA. 
compared with either controls or all children with non-active disease (table 2). Furthermore, during active disease in patients with both oligoarticular and polyarticular JIA, significantly higher IL17 levels were found, whereas in patients with polyarticular and systemic JIA significantly higher MIF levels were found (table 2). In addition, although not significantly higher, IL10 and CCL22 were found in all JIA groups, indicating a possible switch towards a regulatory set of mediators during active disease.

\section{Protein fingerprinting}

Analysis of these data can be masked owing to the large dynamic biological range of cytokine levels in a relatively small patient population. Indeed, our data show that multiple cytokines, such as TNF $\alpha$, IFN $\gamma$ and CCL2, were higher in plasma of patients with JIA during active disease, but this did not reach statistical significance owing to the large variation observed. To visualise these subtle differences, we digitised our data using geometric means, creating colour profiles of each mediator as described previously. ${ }^{25}{ }^{27}$ These protein fingerprints illustrate the higher level of many pro-inflammatory cytokines such as IL6, IL12, TNF $\alpha$, IFN $\gamma$, CCL2, CCL3, CXCL9 and CXCL10 that were observed in all JIA subtypes during active disease. Also, the extremely high IL18 levels in patients with systemic JIA during both remission and active disease are clearly illustrated (fig 2A).

\section{Cytokine signatures in synovial fluid}

In 34 children with active disease, cytokine levels in synovial fluid were compared with paired plasma samples. Significantly higher levels of IL6, IL15, CCL2, CCL3, CXCL8, CXCL9 and CXCL10 were found in synovial fluid compared with plasma of all JIA subtypes, whereas levels of MIF, CCL5 and sCD54 (soluble intracellular adhesion molecule 1) were significantly lower in synovial fluid of all JIA subtypes. CCL18 (pulmonary and activation-regulated chemokine) levels were significantly higher in synovial fluid of both oligoarticular and polyarticular JIA, whereas patients with systemic JIA had higher ILI $\alpha$ levels in synovial fluid. In addition, synovial fluid from patients with oligoarticular JIA contained significantly increased levels of IL10 (table 3). Subsequently, data of paired plasma and synovial fluid from the subtype of JIA were digitised as described above. Using this colour profile, a trend of lower sCD106 (soluble vascular cell adhesion molecule 1) was observed in synovial fluid of patients with JIA, especially patients with systemic JIA, in whom synovial fluid values were 10-fold lower compared with plasma. Summarising, the profiles found in synovial fluid from patients with oligoarticular and polyarticular JIA were similar, whereas the profiles in synovial fluid of patients with systemic JIA show a different pattern, with higher levels of IL1, IL6 and IL18 (fig 2B).

\section{Clinical discrimination using cytokine and chemokine profiles}

To examine whether cytokine profiles can help in stratifying patients with JIA into a specific subclass, we performed both a cluster analysis and a discrimination analysis. For the cluster analysis, we divided the patients into two groups according to their disease status at the time of sampling to see whether particular cytokines cluster together. During remission, a

Table 3 Cytokine levels in paired plasma and synovial fluid samples

\begin{tabular}{|c|c|c|c|c|c|c|}
\hline \multirow[b]{2}{*}{ Mediator } & \multicolumn{2}{|c|}{ Oligoarticular JIA } & \multicolumn{2}{|c|}{ Polyarticular JIA } & \multicolumn{2}{|l|}{ Systemic JIA } \\
\hline & Plasma & SF & Plasma & SF & Plasma & SF \\
\hline $\operatorname{IL} 1 \alpha$ & $22(10)$ & $17(6.2)$ & $40(40)$ & $11(6.1)$ & 3.4 (1.7) & 32 (8.3)† \\
\hline ILI $\beta$ & $24(8.9)$ & $10(2.9)$ & $81(70)$ & 15 (3.7) & $0.2(0.2)$ & 30 (9.2) \\
\hline IL2 & $5.6(3.3)$ & $5.1(1.9)$ & $7.7(7.2)$ & $2.7(1.9)$ & $0.6(0.4)$ & $10(3.3)$ \\
\hline IL4 & $6.8(2.7)$ & $4.9(1.8)$ & 32 (31) & $4.1(2.4)$ & $3.0(3.1)$ & 19 (5.2) \\
\hline IL5 & $3.6(1.5)$ & $20(9.1)$ & $58(58)$ & $18(14)$ & $0.0(0.0)$ & $8.8(1.9)$ \\
\hline IL6 & $827(591)$ & $2641(541) \S$ & $572(345)$ & 2990 (1332)† & 32 (11) & 2645 (2193)‡ \\
\hline IL10 & $9.3(3.1)$ & $52(10) \dagger$ & 91 (89) & $25(8.1)$ & $7.7(6.1)$ & $13(3.0)$ \\
\hline IL12 & $24(5.5)$ & $93(43)$ & 25 (16) & 77 (55) & $51(41)$ & 67 (34) \\
\hline IL13 & $25(10)$ & $10(2.8)$ & 57 (49) & 13 (3.9) & $1.2(0.8)$ & $21(3.0)$ \\
\hline IL15 & $0.7(3.8)$ & $19(6.8) \dagger$ & $4.1(4.1)$ & $12(3.1) \dagger$ & $1.2(0.8)$ & $14(6.1) \dagger$ \\
\hline IL17 & 625 (347) & 27 (7.7) & $186(174)$ & $8.0(3.2)$ & $2.3(2.3)$ & $14(5.7)$ \\
\hline IL18 & $110(26)$ & $118(17)$ & $135(36)$ & $68(22)$ & 4147 (1682) & 1779 (1051) \\
\hline $\mathrm{TNF} \alpha$ & $21(8.9)$ & $10(4)$ & $36(31)$ & $13(4.2)$ & $0.6(1.6)$ & $54(43)$ \\
\hline $\mathrm{IFN} \gamma$ & $282(144)$ & $176(77)$ & 253 (215) & $163(82)$ & $84(56)$ & 171 (132) \\
\hline OSM & 482 (336) & 194 (161) & $30(22)$ & 3.5 (1.7) & $2.1(1.1)$ & 19 (19) \\
\hline MIF* & $5.2(1.4)$ & $0.3(0.2) \ddagger$ & 24 (10) & $1.7(1.4) \S$ & 11 (1.9) & $2.0(8.8) \dagger$ \\
\hline $\mathrm{CCL} 2$ & $107(23)$ & $5455(1816) \S$ & 74 (28) & 6129 (1516)‡ & $33(23)$ & $245(187) \dagger$ \\
\hline CCL3 & 1907 (513) & 3731 (1742)† & 1902 (1359) & 7971 (3938)‡ & $132(84)$ & $6289(1786) \S$ \\
\hline $\mathrm{CCL}^{*}$ & $174(55)$ & $0.7(0.2) \S$ & $96(24)$ & $0.6(0.2) \S$ & $68(12)$ & $1.5(0.6) \S$ \\
\hline CCL11 & 106 (33) & $2068(900) \S$ & 70 (27) & $781(561) \ddagger$ & 36 (27) & 53 (16) \\
\hline CCL17 & 102 (19) & $31(6.3)$ & 71 (28) & $11(3.3)$ & 56 (33) & 27 (10) \\
\hline CCL18* & $55(22)$ & $12(1.3) \S$ & $69(42)$ & $11(2.1) \S$ & 23 (10) & 75 (68) \\
\hline CCL22 & $1867(504)$ & $1317(250)$ & 869 (367) & $820(310)$ & $294(125)$ & $112(47)$ \\
\hline CXCL8 & $421(365)$ & 1884 (1348)‡ & $124(78)$ & $1513(1481) \S$ & $1.0(0.9)$ & $2928(2061) \ddagger$ \\
\hline CXCL9 & 177 (77) & 2817 (844)‡ & $154(90)$ & $2266(123.7) \ddagger$ & 4.1 (2.2) & 85 (19)‡ \\
\hline CXCL10 & 1091 (296) & 4001 (959)‡ & 455 (215) & 5128 (1759)§ & $193(75)$ & $2772(1443) \ddagger$ \\
\hline OPG* & $8.7(3.7)$ & $4.5(1.4)$ & $4.2(28)$ & $5.8(2.7)$ & $1.4(1.1)$ & $1.7(1.3)$ \\
\hline sRANKL & $4.6(4.1)$ & $16(6.2)$ & $55(55)$ & $12.4(8.1)$ & $2.3(1.1)$ & $1.3(2.4)$ \\
\hline sCD54* & $110(22)$ & 75 (13)† & 113 (19) & 57 (17)‡ & $141(6.7)$ & $57(23) \ddagger$ \\
\hline sCD106* & 748 (79) & $658(45)$ & 813 (47) & $506(182)$ & 603 (154) & 67 (16)§ \\
\hline
\end{tabular}

IFN, interferon; IL, interleukin; JIA, juvenile idiopathic arthritis; MIF, macrophage inhibitory factor; OPG, osteoprotergerin; OSM, oncostatin $M$; sRANKL, soluble receptor activator of nuclear factor- $\kappa$ B ligand; SF, synovial fluid; TNF, tumour necrosis factor.

${ }^{*}$ All values (mean (SD)) are expressed in $\mathrm{pg} / \mathrm{ml}$ (except for those marked * which are in $\mathrm{ng} / \mathrm{ml}$ ).

†Significant difference between plasma and synovial fluid of each specified subtype of JIA; $p<0.05$

\#Significant difference between plasma and synovial fluid of each specified subtype of JIA; $p<0.01$.

$\S$ Significant difference between plasma and synovial fluid of each specified subtype of JIA; $p<0.001$ 


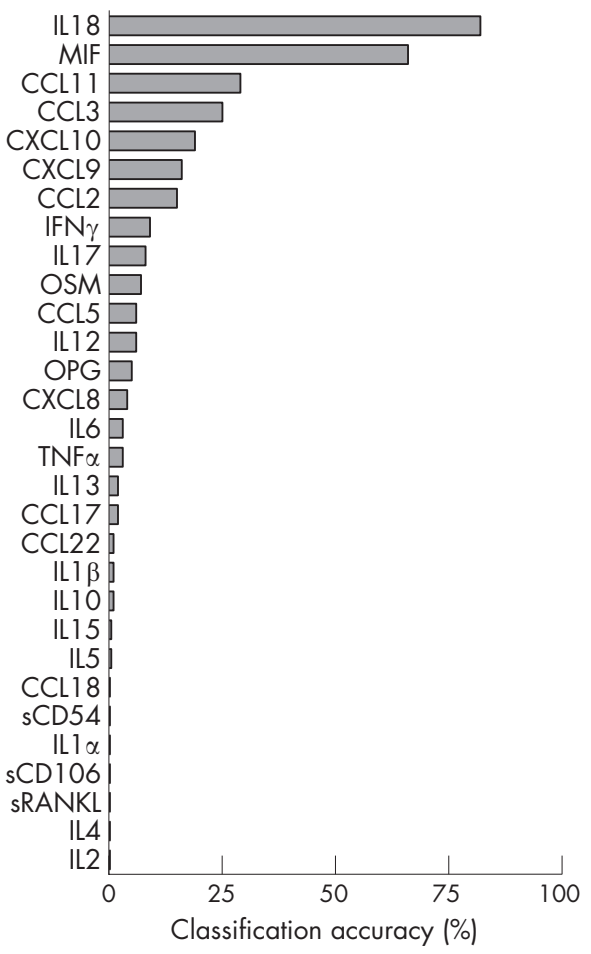

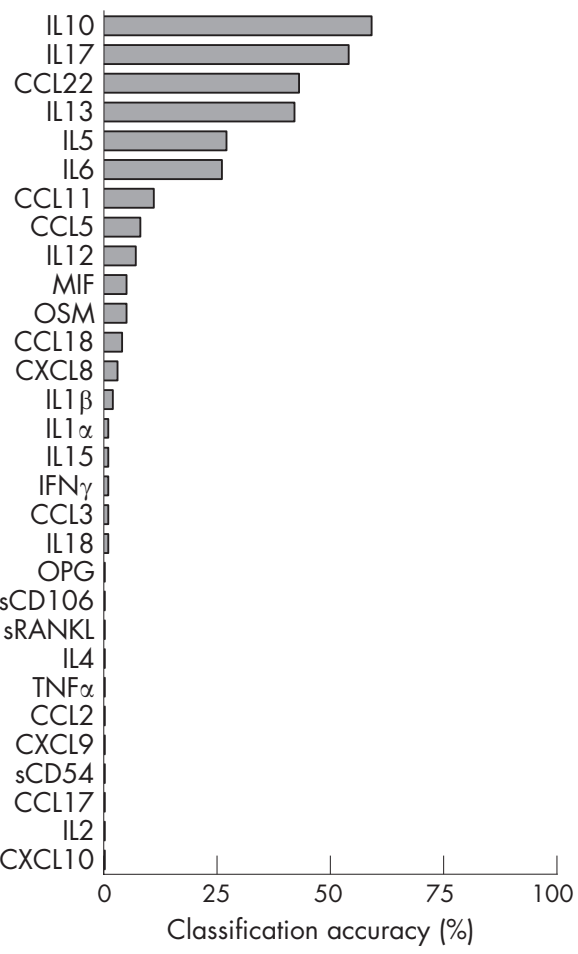

Figure 3 Discrimination analyses of each individual cytokine. All cytokines are ranked on classification accuracy. Left panel, active disease; right panel, remission. IL, interleukin; MIF, macrophage inhibitory factor. number of cytokines with either a regulatory or an antiinflammatory function cluster together with either increased or decreased levels in plasma (IL5, IL6, IL10, IL13, IL17, CCL22), whereas during active disease, most of the pro-inflammatory cytokines cluster (IL17, IL18, IFN $\gamma$, MIF, CCL2, CCL3, CXCL9, CXCL10). When a cluster analysis was performed using the patients with diabetes, the increased pro-inflammatory cytokines CCL2 and CXCL8 cluster together.

Next, we performed a discrimination analysis using the three major JIA subtypes. For accurate prediction, a backward calculation using blinded samples was made (including the controls) to see whether we could accurately classify them into a specific subgroup of JIA (fig 3). Owing to the large biological presence of cytokines, care should be taken to discriminate only those based on one mediator. However, it appeared that MIF levels in particular, can be used for discrimination, as overall $66 \%$ of all patients with JIA were predicted correctly. This was especially the case for patients with oligoarticular JIA $(80 \%$ classified correct) but not for patients with polyarticular and systemic JIA (only $35 \%$ and $23 \%$ predicted correctly, respectively). When the same analysis was made for patients in remission, the best discriminative values were found for IL10 and IL17, although both were $<60 \%$ accurate throughout all subgroups (fig 3 ).

Using this mathematical approach, ILl8 can predict, with 93\% accuracy, patients with active systemic JIA, when all samples are tested blinded. The predictive value of IL18 is far lower for patients with oligoarticular and polyarticular JIA. In fact, IL18 levels were not superior to ESR or CRP levels in determination of active disease in patients with oligoarticular and polyarticular JIA. ESR and CRP were significantly correlated with active disease for all patients with JIA $(\mathrm{p}<0.05$ for both ESR and CRP), but no correlation was found for either parameter with IL18 in oligoarticular and polyarticular JIA (fig 4). IL18 does correlate with ESR and CRP levels in patients with systemic JIA (fig 4), but not with other proposed activation markers for systemic JIA such as ferritin ${ }^{31}(p=0.350$, data not shown). Subsequently, we tested whether a discrimination profile of multiple cytokines could help in determining JIA subclassification. From our data, a panel of the following cytokines could be deducted for subtype analysis; IL18, MIF, CCL2, CCL3, CCL11, CXCL9 and CXCL10. Figure 5 shows the cytokine levels in plasma among each subtype of JIA that were identified with the discrimination analysis. Significantly higher levels of CCL2, CCL11 and CXCL10 were present in plasma of oligoarticular JIA compared with the systemic form of JIA, whereas CCL2 showed a trend towards significance $(p=0.055$; fig 5). ILl8 levels in plasma of patients with systemic JIA were significantly increased compared with both oligoarticular and polyarticular JIA (fig 5).

\section{Subgroup analysis}

Since patient numbers are small, in this study we enrolled the patients with extended oligoarticular JIA in the group of patients with polyarticular JIA based on their clinical characteristics. In our study, five patients with extended oligoarticular JIA were present in the polyarticular group. When the cytokine profile of these five patients with extended oligoarticular JIA was compared with the patients with persistent oligoarticular JIA, no significant differences were found. Although IL17 levels seem higher in patients with persistent oligoarticular JIA compared with patients with extended oligoJIA (2395 (2322) vs $172(450) \mathrm{pg} / \mathrm{ml})$, this is mainly because of one patient with extremely high levels of ILl7 (7544 pg/ml). When this patient is excluded from the analysis, the average levels of IL17 of the patients with persistent oligoarticular JIA are similar to patients with extended oligoarticular JIA (316 (174) vs $172(450) \mathrm{pg} / \mathrm{ml})$.

Furthermore, Ravelli et $a^{32}$ suggested a hypothesis of a homogenous group of patients with both oligoarticular and polyarticular JIA which is characterised by antinuclear antibody (ANA) positivity rather than joint course. To investigate whether cytokines are involved in such a subgroup, we divided the patients based on ANA positivity irrespective of joint course. 

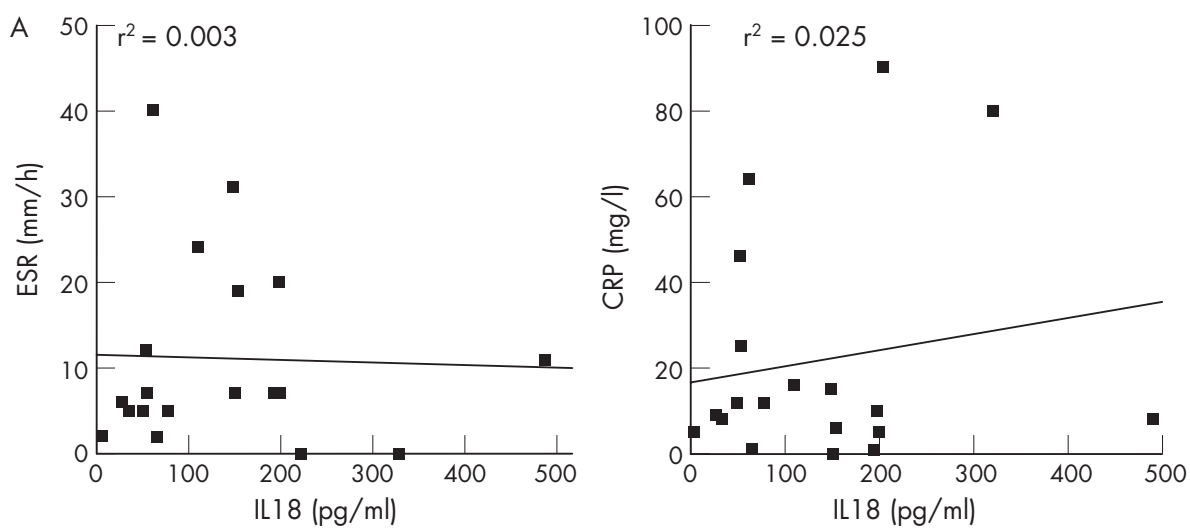

Figure 4 Correlations between interleukin (IL) 18 and erythrocyte sedimentation rate (ESR) /C reactive protein (CRP). Correlations between IL18 levels in plasma and ESR (left panel) or CRP levels (right panel). (A)

Oligoarticular juvenile idiopathic arthritis (JIA); (B) polyarticular JIA; (C) systemic JIA. IFN, interferon; MIF, macrophage inhibitory factor; OPG, osteoprotergerin; OSM, oncostatin $M$; sRANKL, soluble receptor activator of nuclear factor $\kappa$ B ligand; TF, tumour necrosis factor.
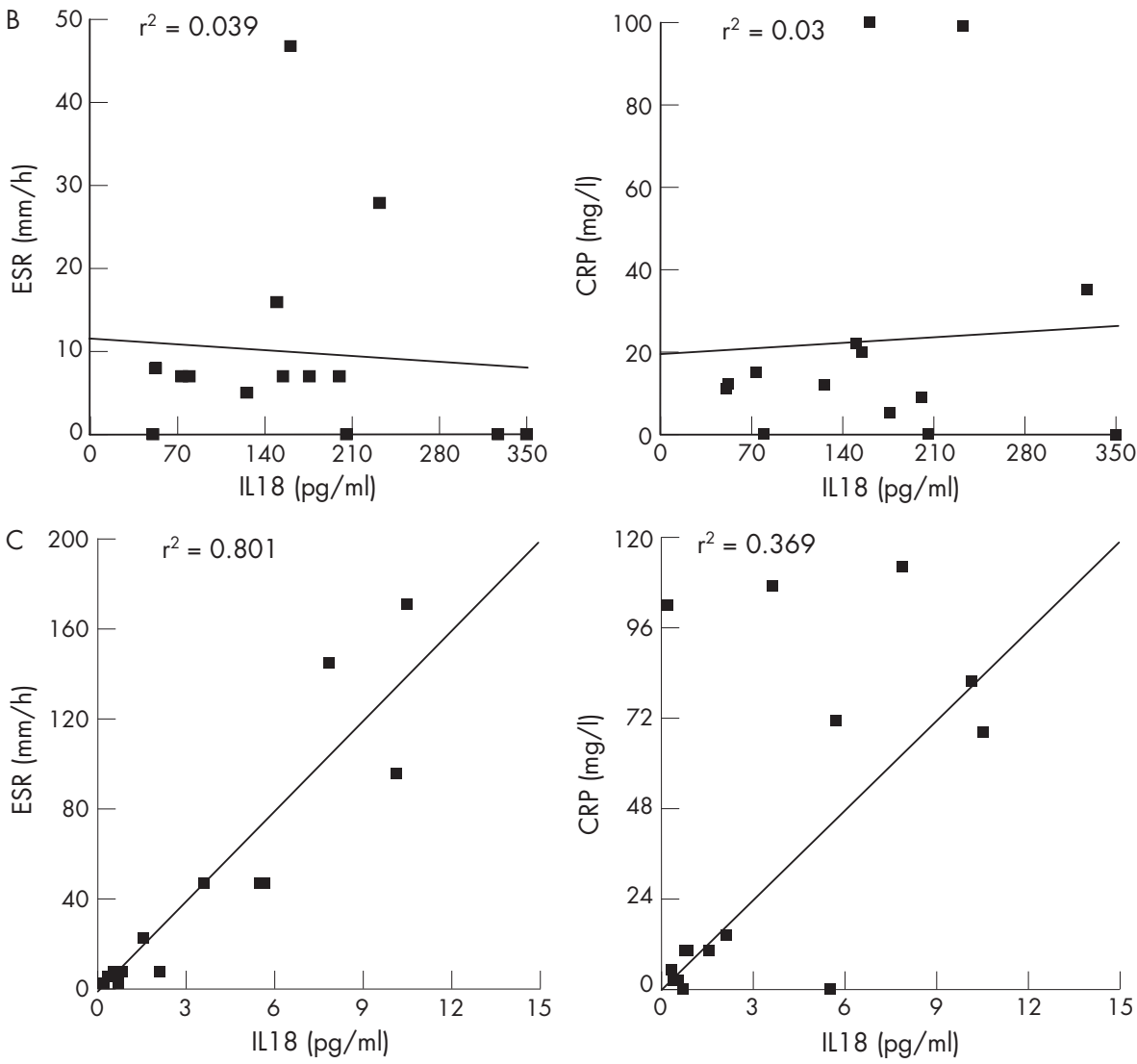

When we compared the cytokine signatures in plasma, there were no significant differences between ANA-positive and ANA-negative patients.

\section{DISCUSSION}

Characterisation of cytokine and chemokine profiles in plasma and synovial fluid of patients with JIA, as well as genetic profiling of the (innate) immune system, can provide knowledge about the pathogenesis of this autoimmune disease. Indeed, different genes involving cytokines and chemokines are linked to JIA and result in functional changes in the cytokine and chemokine profiles. ${ }^{33}$ Confirmation of linkage with disease has been reported for IL6, TNF $\alpha$, IL10 and MIF, whereas other studies show a possible linkage for ILl and IL4. ${ }^{11}{ }^{12}{ }^{34-36}$ In addition, during the ongoing inflammatory process many mediators are produced, resulting in increased levels of proinflammatory cytokines (ILs and chemokines). ${ }^{8-10} 18$ 35-43
Monitoring changes in these cytokine signatures may function as therapeutic and possibly even as prognostic biomarkers for disease. In previous studies, individual cytokines, or at best, combinations of a limited set of cytokines have been measured in plasma and synovial fluid of patients with JIA using conventional ELISA techniques. The MIA allows multiplex analysis of up to a hundred different mediators in a single sample and thus can be useful tool for measurement of cytokines in small sample volumes, such as samples from paediatric patients. ${ }^{26}$

We now report the profile of a full spectrum of cytokines, chemokines, and soluble adhesion molecules in plasma and synovial fluid of patients with JIA, measured in a single sample. Even during apparent clinical remission, we detected increased levels of several inflammatory proteins in plasma of patients with JIA. However, the inflammatory profile is not completely disease specific since patients with chronic inflammatory 

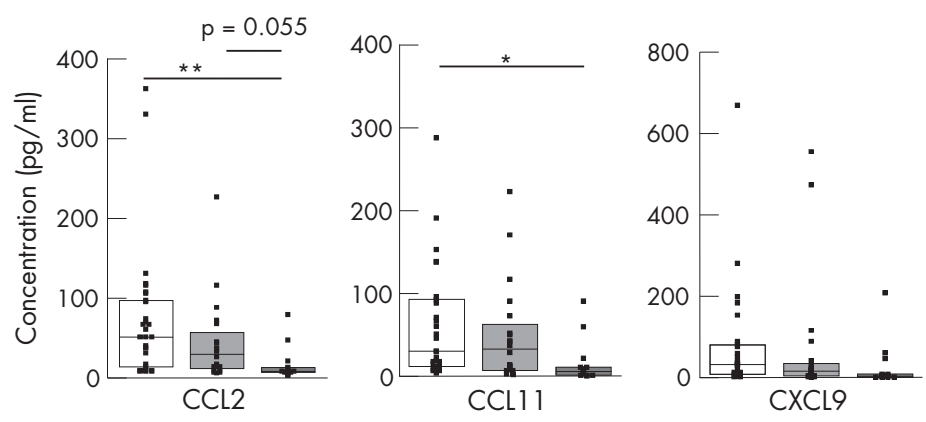

Figure 5 Cytokine and chemokine concentrations in plasma of different subtypes of juvenile idiopathic arthritis (JIA). The cytokines that have the best discriminative value when each subtype of JIA was compared with the whole study population of patients with JIA are depicted. Oligoarticular JIA (open bars), polyarticular JIA (light grey bars), systemic JIA (dark grey bars). ${ }^{\star} p<0.05,{ }^{* *} p<0.01$. CRP, C-reactive protein; ESR, erythrocyte sedimentation rate; IL, interleukin.
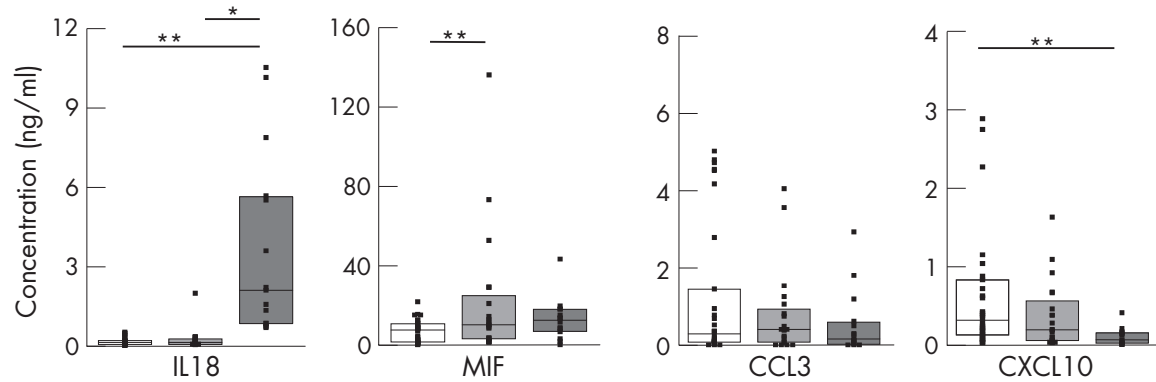

diseases, such as patients with diabetes, also show moderately increased cytokine profiles of CCL2, CXCL8 and CXCL10 (table 2). Using a cluster analysis, these cytokines were found to be present for patients with both JIA and diabetes.

During active disease, cytokine concentrations in plasma of patients with JIA increased 2-35-fold. In synovial fluid, which originates from the compartment where the inflammatory process takes place, high levels of IL6, IL15, CCL2, CCL3, CXCL8, CXCL9 and CXCL10 are present. These cytokines regulate $\mathrm{T}$ cell function and $\mathrm{T}$ cell proliferation, whereas the chemokines have similar overlapping functions mainly based on cellular recruitment of inflammatory $\mathrm{T}$ lymphocytes ( $\mathrm{T}$ helper (Th)l cells) and monocytes to the site of inflammation. ${ }^{37}{ }^{44}$ In contrast with high levels of Thl-attracting chemokines, two distinct Th2 markers, CCL1l and CCL22 were also increased in synovial fluid of patients with oligoarticular and polyarticular JIA, but not in systemic JIA. These chemokines might play a role in controlling synovial inflammation, and counterbalance the dominant inflammatory milieu by attracting regulatory $\mathrm{T}$ cells. ${ }^{45}$ Cluster analysis showed a distinct inflammatory pattern of inflammatory proteins in combination with increased levels of IL10 and CCL22 during active disease, whereas a more regulatory and anti-inflammatory cluster was observed, especially in oligoarticular JIA, during remission (table 2). Furthermore, one particular cytokine, IL17, was present in both clusters. This cytokine, which is increased in plasma of patients with both oligoarticular and polyarticular but not in patients with systemic JIA, is produced by a new identified lineage of effector Th cells, named Th17. ${ }^{46} 47$ The presence of IL17 may reflect the presence and/or involvement of these cells in the immunopathogenesis of oligoarticular and polyarticular JIA.

No differences were found when plasma levels of IL17 (or any other cytokine) were compared between persistent and extended oligoarticular JIA, nor could we detect differences between ANApositive and ANA-negative patients in this cross-sectional study. However, a prospective study of patients with oligoarticular JIA at onset of disease may be needed to address this properly.

Another novel aspect of the results in the perspective of the current literature is that a spectrum of cytokines might be useful (besides clinical assessment) in determining a set of discriminative parameters for JIA subgroup classification and disease activity. Our data suggest that a combination of cytokines (IL18, MIF, CCL2, CCL3, CCL11 CXCL9 and CXCL10) can be used as a discriminative panel in JIA. In contrast with JIA, in adult rheumatoid arthritis different cytokines are relevant. A distinct but transient cytokine pattern can be used for accuracy of disease classification in early rheumatoid arthritis and consists of IL2, IL4, IL13, IL15 and IL17. ${ }^{38}$

The clear difference in cytokine pattern between systemic JIA and oligoarticular or polyarticular JIA underscores that systemic JIA most probably has a different aetiopathology. Besides different cytokine patterns, there is considerable evidence for natural killer (NK) cell dysfunction in systemic JIA compared with the other subtypes of JIA. ${ }^{183} 48$ We and others observed high levels of IL18 in plasma of children with systemic JIA. ${ }^{49}$ It is known that IL18 activates NK cells and thus the chronic presence of high circulating levels of IL18 might depress NK activity by either exhausting or lowering sensitivity to IL18. ${ }^{50}$ Interestingly, the IL18 pathway uses similar routing as ILl, and blocking the ILl pathway results in good clinical responses in systemic JIA. ${ }^{18}$

In our patient population, we found strikingly lower IL6 values in plasma of patients with systemic JIA compared with patients with oligoarticular and polyarticular JIA, whereas several studies show an increase in IL6 in systemic JIA. ${ }^{40-53}$ This could be due to the fact that circulating cytokines can be bound to their soluble receptors and thus can result in an underestimation of the true cytokine concentration. For instance, specific binding of ILl, IL6 and IL18 to their soluble receptors or their binding proteins is well documented. ${ }^{54}$ Moreover, since IL6 levels are negatively correlated with the concentration of soluble receptors in JIA, one could hypothesise that this binding is even more vigorous in synovial fluid. ${ }^{51} 53$ Furthermore, since we used a multiplex liquid-phase assay for detection of cytokines instead of regular ELISA, binding proteins for cytokines such as IL6 and IL18 can influence the assay. ${ }^{55}$

The time of collecting the blood sample and stratifying disease activity is important. Activities of a number of cytokines have been demonstrated to be under under neuro-endocrine 
control and thus have a diurnal rhythm..$^{56} 57$ These fluctuating cytokine levels are extremely low or undetectable in healthy people but might explain conflicting results in diseased individuals. ${ }^{58} 59$ In this study, all samples were taken in the morning, thus limiting this diurnal effect.

This cross-sectional study shows the power of the MIA to analyse cytokine profiles in autoimmune disease. Obviously, interpretation of cytokine analysis in plasma has to be done with caution. This "cyto-omic" approach may help to assess the role of these molecules in immunopathogenesis, but plasma cytokines can never be more than a reflection of the complex immune processes underlying the disease.

In conclusion, our data show a significant predominant proinflammatory cytokine signature in plasma and synovial fluid of patients with JIA, especially during active disease. Remarkably, even in remission, multiple inflammatory cytokines such as IL6 and IFN $\gamma$ still exceed the normal levels as observed in healthy individuals. This may be of importance in determining the treatment during apparent clinical disease remission. We present a specific panel of cytokines (ILs and chemokines) that can be useful to stratify different subtypes of JIA and improve the design of cytokine-targeted treatment for patients with autoimmune-mediated diseases. The clinical value of this panel will have to be determined in future prospective studies of well-defined and selected patient populations.

\section{ACKNOWLEDGEMENTS}

We thank CS Uiterwaal, the Julius Center for Health Sciences and Primary Care, University Medical Center Utrecht, and EP Martens, the Center for Biostatistics, Utrecht University, for advice with statistical and data analysis.

\section{Authors' affiliations}

\section{Wilco de Jager, Nico M Wulffraat, Wietse Kuis, Berent J Prakken,}

Department of Pediatric Immunology, University Medical Center Utrecht, Utrecht, The Netherlands; IACOPO Institute for Translational Medicine, Utrecht, The Netherlands; San Diego, California, USA

Esther P A H Hoppenreijs, Department of Pediatrics, University Medical Center Nijmegen, Niimegen, The Netherlands

Lucy R Wedderburn, Rheumatology Unit, Institute of Child Health, University College, London, UK

Funding: WdJ and BJP are financially supported by the Dutch Rheumatoid Arthritis Foundation (Nationaal Reumafonds) and by the Immune Tolerance Network (ITN). Furthermore, BJP is supported by a VIDI innovation grant from the Dutch Organization for Scientific Research (NWO). LRW is supported by grants from SPARKS UK and the Arthritis Research Campaign.

Competing interests: None.

\section{REFERENCES}

1 Prahalad S. Genetics of juvenile idiopathic arthritis: an update. Curr Opin Rheumatol 2004; 16:588-94.

2 Choy EH, Panayi GS. Cytokine pathways and joint inflammation in rheumatoid arthritis. N Engl J Med 2001;344:907-16.

3 Woo P. Cytokines and juvenile idiopathic arthritis. Curr Rheumatol Rep 2002;4:452-7.

4 Baggiolini M. Chemokines and leukocyte traffic. Nature 1998;392:565-8.

5 Luster AD. Chemokines - chemotactic cytokines that mediate inflammation. N Engl J Med 1998;338:436-45

6 O'Shea JJ, Ma A, Lipsky P. Cytokines and autoimmunity. Nat Rev Immunol 2002;2:37-45.

7 Trautmann A. Chemokines as immunotransmitters? Nat Immunol 2005;6:427-8.

8 De Benedetti F, Pignatti P, Bernasconi S, Gerloni V, Matsushima K, Caporali R, ef al. Interleukin 8 and monocyte chemoattractant protein-1 in patients with juvenile rheumatoid arthritis. Relation to onset types, disease activity, and synovial fluid leukocytes. J Rheumatol 1999;26:425-31.

9 Ozen S, Saatci U, Bakkaloglu A, Ozdemir O, Besbas N, Kirazli S, et al. Interleukin-1,-6, and -8 levels in juvenile chronic arthritis. Clin Rheumato $1997 ; 16: 173-8$

10 Yilmaz M, Kendirli SG, Altintas D, Bingol G, Antmen B. Cytokine levels in serum of patients with juvenile rheumatoid arthritis. Clin Rheumatol 2001;20:30-5.
11 Crawley E, Kon S, Woo P. Hereditary predisposition to low interleukin-10 production in children with extended oligoarticular juvenile idiopathic arthritis. Rheumatology (Oxford) $2001 ; 40: 574-8$.

12 De Benedetti F, Meazza C, Vivarelli M, Rossi F, Pistorio A, Lamb R, et al. Functional and prognostic relevance of the -173 polymorphism of the macrophage migration inhibitory factor gene in systemic-onset juvenile idiopathic arthritis. Arthritis Rheum 2003;48:1398-407.

13 Barnes DA, Tse J, Kaufhold M, Owen M, Hesselgesser J, Strieter R, et al. Polyclonal antibody directed against human RANTES ameliorates disease in the Lewis rat adjuvant-induced arthritis model. J Clin Invest 1998;101:2910-19.

14 Lovell DJ, Giannini EH, Reiff A, Cawkwell GD, Silverman ED, Nocton JJ, et al. Etanercept in children with polyarticular juvenile rheumatoid arthritis. Pediatric Rheumatology Collaborative Study Group. N Engl J Med 2000;342:763-9.

15 Yokota S. Interleukin 6 as a therapeutic target in systemic-onset juvenile idiopathic arthritis. Curr Opin Rheumatol 2003;15:581-6.

16 Steinman L. Immune therapy for autoimmune diseases. Science 2004;305:212-16

17 Haringman JJ, Tak PP. Chemokine blockade: a new era in the treatment of rheumatoid arthritis? Arthritis Res Ther 2004:6:93-7.

18 Pascual V, Allantaz F, Arce E, Punaro M, Banchereau J. Role of interleukin-1 (IL$1)$ in the pathogenesis of systemic onset juvenile idiopathic arthritis and clinical response to IL-1 blockade. J Exp Med 2005;201:1479-86.

19 Charo IF, Ransohoff RM. The many roles of chemokines and chemokine receptors in inflammation. N Engl J Med 2006;354:610-21.

20 Blanco P, Palucka AK, Gill M, Pascual V, Banchereau J. Induction of dendritic cell differentiation by IFN-alpha in systemic lupus erythematosus. Science $2001 ; 294: 1540-3$

21 Shakoor N, Michalska M, Harris CA, Block JA. Drug-induced systemic lupus erythematosus associated with etanercept therapy. Lancet 2002;359:579-80.

22 Goodyear M. Learning from the TGN1412 trial. BMJ 2006;332:677-8.

23 Mayor S. Severe adverse reactions prompt call for trial design changes. BMJ 2006;332:683.

24 Suntharalingam G, Perry MR, Ward S, Brett SJ, Castello-Cortes A, Brunner MD, et al. Cytokine storm in a phase 1 trial of the anti-CD28 monoclonal antibody TGN1412. N Engl J Med 2006;355:1018-28.

25 de Jager W, Te Velthuis H, Prakken BJ, Kuis W, Riikers GT. Simultaneous detection of 15 human cytokines in a single sample of stimulated peripheral blood mononuclear cells. Clin Diagn Lab Immunol 2003;10:133-9.

26 Vignali DA. Multiplexed particle-based flow cytometric assays. J Immunol Methods 2000;243:243-55

27 de Jager W, Prakken BJ, Biilsma JW, Kuis W, Rijkers GT. Improved multiplex immunoassay performance in human plasma and synovial fluid following removal of interfering heterophilic antibodies. J Immunol Methods 2005;300:124-35

28 Petty RE, Southwood TR, Baum J, Bhettay E, Glass DN, Manners P, et al. Revision of the proposed classification criteria for juvenile idiopathic arthritis: Durban, 1997. J Rheumatol 1998;25:1991-4.

29 Petty RE, Southwood TR, Manners P, Baum J, Glass DN, Goldenberg J, et al. International League of Associations for Rheumatology classification of juvenile idiopathic arthritis: second revision, Edmonton, 2001. J Rheumatol 2004;31:390-2.

30 Kamphuis S, Kuis W, de Jager W, Teklenburg G, Massa M, Gordon G, et al. Tolerogenic immune responses to novel T-cell epitopes from heat-shock protein 60 in juvenile idiopathic arthritis. Lancet 2005;366:50-6.

31 Ravelli A, Magni-Manzoni S, Pistorio A, Besana C, Foti T, Ruperto N, et al. Preliminary diagnostic guidelines for macrophage activation syndrome complicating systemic juvenile idiopathic arthritis. J Pediatr 2005; 146:598-604

32 Ravelli A, Felici E, Magni-Manzoni S, Pistorio A, Novarini C, Bozzola E, et al. Patients with antinuclear antibody-positive juvenile idiopathic arthritis constitute a homogeneous subgroup irrespective of the course of joint disease. Arthritis Rheum 2005;52:826-32.

33 Phelan JD, Thompson SD, Glass DN. Susceptibility to JRA/JIA: complementing general autoimmune and arthritis traits. Genes Immun 2006;7:1-10.

34 Fishman D, Faulds G, Jeffery R, Mohamed-Ali V, Yudkin JS, Humphries S, et al. The effect of novel polymorphisms in the interleukin- 6 (IL-6) gene on IL-6 transcription and plasma IL-6 levels, and an association with systemic-onse juvenile chronic arthritis. J Clin Invest 1998;102:1369-76.

35 Ozen S, Alikasifoglu M, Bakkaloglu A, Duzova A, Jarosova K, Nemcova D, et al. Tumour necrosis factor alpha $G \rightarrow A-238$ and $G \rightarrow A-308$ polymorphisms in juvenile idiopathic arthritis. Rheumatology (Oxford) 2002;41:223-7.

36 Zeggini E, Thomson W, Kwiatkowski D, Richardson A, Ollier W, Donn R. Linkage and association studies of single-nucleotide polymorphism-tagged tumor necrosis factor haplotypes in juvenile oligoarthritis. Arthritis Rheum 2002:46:3304-11.

37 Pharoah DS, Varsani H, Tatham RW, Newton KR, de Jager W, Prakken BJ, et al. Expression of the inflammatory chemokines CCL5, CCL3 and CXCL10 in juvenile idiopathic arthritis, and demonstration of CCL5 production by an atypical subse of CD8+ T cells. Arthritis Res Ther 2006:8:R50.

38 Raza K, Falciani F, Curnow SJ, Ross E, Lee CY, Akbar A, et al. Early rheumatoid arthritis is characterized by a distinct and transient synovial fluid cytokine profile of T cell and stromal cell origin. Arthritis Res Ther 2005;7:R784-95.

39 Ou LS, See LC, Wu CJ, Kao CC, Lin YL, Huang JL. Association between serum inflammatory cytokines and disease activity in juvenile idiopathic arthritis. Clin Rheumatol 2002;21:52-6.

40 Lepore L, Pennesi M, Saletta S, Perticarari S, Presani G, Prodan M. Study of IL-2, IL-6, TNF alpha, IFN gamma and beta in the serum and synovial fluid of patients with juvenile chronic arthritis. Clin Exp Rheumatol 1994;12:561-5.

41 De Benedetti F, Ravelli A, Martini A. Cytokines in juvenile rheumatoid arthritis. Curr Opin Rheumatol 1997;9:428-33. 
42 Gattorno M, Picco P, Vignola S, Stalla F, Buoncompagni A, Pistoia V. Serum interleukin 12 concentration in juvenile chronic arthritis. Ann Rheum Dis 1998; $57: 425-8$

43 De Benedetti $F$, Vivarelli $M$, Pignatti $P$, Oliveri $M$, Massa $M$, Pistorio A, et al. Circulating levels of soluble E-selectin, P-selectin and intercellular adhesion molecule- 1 in patients with juvenile idiopathic arthritis. J Rheumato 2000;27:2246-50.

44 Charo IF, Ransohoff RM. The many roles of chemokines and chemokine receptors in inflammation. N Engl J Med 2006;354:610-21.

45 lellem A, Mariani M, Lang R, Recalde H, Panina-Bordignon P, Sinigaglia F, et al. Unique chemotactic response profile and specific expression of chemokine receptors CCR4 and CCR8 by CD4(+)CD25(+) regulatory T cells. J Exp Med 2001;194:847-53.

46 Harrington LE, Hatton RD, Mangan PR, Turner H, Murphy TL, Murphy KM, et al. Interleukin 17-producing CD4+ effector T cells develop via a lineage distinct from the T helper type 1 and 2 lineages. Nat Immunol 2005;6:1 123-32.

47 Park H, Li Z, Yang XO, Chang SH, Nurieva R, Wang YH, et al. A distinct lineage of CD4 T cells regulates tissue inflammation by producing interleukin 17. Nat Immunol 2005:6:1133-41.

48 Wulffraat NM, Rijkers GT, Elst E, Brooimans R, Kuis W. Reduced perforin expression in systemic juvenile idiopathic arthritis is restored by autologous stemcell transplantation. Rheumatology (Oxford) 2003;42:375-9.

49 Maeno N, Takei S, Nomura Y, Imanaka H, Hokonohara M, Miyata K. Highly elevated serum levels of interleukin-18 in systemic juvenile idiopathic arthritis but not in other juvenile idiopathic arthritis subtypes or in Kawasaki disease: comment on the article by Kawashima et al. Arthritis Rheum 2002:46:2539-41.

50 Andoniou CE, van Dommelen SL, Voigt V, Andrews DM, Brizard G, AsselinPaturel C, et al. Interaction between conventional dendritic cells and natural killer cells is integral to the activation of effective antiviral immunity. Nat Immunol 2005;6:1011-19.

51 De Benedetti F, Massa M, Pignatti P, Albani S, Novick D, Martini A. Serum soluble interleukin 6 (IL-6) receptor and IL-6/soluble IL-6 receptor complex in systemic juvenile rheumatoid arthritis. J Clin Invest 1994;93:2114-19.

52 Kutukculer N, Caglayan S, Aydogdu F. Study of pro-inflammatory (TNF-alpha, IL-1 alpha, IL-6) and T-cell-derived (IL-2, IL-4) cytokines in plasma and synovial fluid of patients with juvenile chronic arthritis: correlations with clinical and laboratory parameters. Clin Rheumatol 1998;17:288-92.

53 Pignatti P, Ciapponi L, Galle P, Hansen MB, Massa M, Meazza C, et al. High circulating levels of biologically inactive IL-6/SIL-6 receptor complexes in systemic juvenile idiopathic arthritis: evidence for serum factors interfering with the binding to gp130. Clin Exp Immunol 2003;131:355-63.

54 Svenson M, Hansen MB, Heegaard P, Abell K, Bendtzen K. Specific binding of interleukin 1 (IL-1) beta and IL-1 receptor antagonist (IL-1 ra) to human serum. High-affinity binding of IL-1 ra to soluble IL-1 receptor type I. Cytokine 1993:5:427-35.

55 de Jager W, Rijkers GT. Solid-phase and bead-based cytokine immunoassay: a comparison. Methods 2006

56 Petrovsky N, McNair P, Harrison LC. Diurnal rhythms of pro-inflammatory cytokines: regulation by plasma cortisol and therapeutic implications. Cytokine 1998; 10:307-12

57 Petrovsky N, Harrison LC. The chronobiology of human cytokine production. Int Rev Immunol 1998;16:635-49.

58 Gudewill S, Pollmacher T, Vedder H, Schreiber W, Fassbender K, Holsboer F. Nocturnal plasma levels of cytokines in healthy men. Eur Arch Psychiatry Clin Neurosci 1992;242:53-6.

59 Cutolo M, Seriolo B, Craviotto C, Pizzorni C, Sulli A. Circadian rhythms in RA. Ann Rheum Dis 2003;62:593-6.

\section{bmjupdates+}

bmjupdates+ is a unique and free alerting service, designed to keep you up to date with the medical literature that is truly important to your practice.

bmjupdates+ will alert you to important new research and will provide you with the best new evidence concerning important advances in health care, tailored to your medical interests and time demands.

\section{Where does the information come from?}

bmjupdates+ applies an expert critical appraisal filter to over 100 top medical journals A panel of over 2000 physicians find the few 'must read' studies for each area of clinical interest

Sign up to receive your tailored email alerts, searching access and more...

www.bmjupdates.com 


\section{Corrections}

There was an error in table 1 of an article published in the May 2006 issue (Reginster J-Y, Adami S, Lakatos P, Greenwald M, Stepan JJ, Silverman SL. Efficacy and tolerability of oncemonthly oral ibandronate in postmenopausal osteoporosis: 2 year results from the MOBILE study. Ann Rheum Dis 2006; 65:654-661). In the header row of table 1 "50 + 5 mg monthly ( $\mathrm{n}=396)$ " should read "50 + $50 \mathrm{mg}$ monthly $(\mathrm{n}=396)$ ".

Ann Rheum Dis 2008;67:280. doi:10.1136/ard.2005.044958.corr1

An error occurred in table 1 of a paper published in the May 2007 issue (de Jager W, Hoppenreijs PAH, Wulffraat NM, Wedderburn LR, Kuis W, Prakken BJ. Blood and synovial fluid cytokine signatures in patients with juvenile idiopathic arthritis: a cross-sectional study. Ann Rheum Dis 2007;66:589-98). The correct table is available online at http://ard.bmj.com/contents/ vol67/issue2.

Ann Rheum Dis 2008;67:280. doi:10.1136/ard.2006.061853.corr1
Furst DE, Breedveld FC, Kalden JR, Smolen JS, Burmester GR, Sieper J, et al. Updated consensus statement on biological agents for the treatment of rheumatic diseases, 2007. Ann Rheum Dis 2007;66(Suppl III):iii2-22

This article mistakenly identifies all three anti-TNF agents (adalimumab, etanercept and infliximab) as having approval for the indication of juvenile idiopathic arthritis of the polyarticular type. Currently only etanercept holds this indication. The cited references to support the statement (refs 60-62) are all publications concerning etanercept.

Ann Rheum Dis 2008;67:280. doi:10.1136/ard.2007.081430.corr1

The authors of the article "Long-term follow-up results after autologous haematopoietic stem cell transplantation for severe systemic sclerosis" published in Ann Rheum Dis 2008;67:98-104 should have been listed in the following order: M C Vonk, Z Marjanovic, F H J van den Hoogen, S Zohar, A V M B Schattenberg, W E Fibbe, J Larghero, E Gluckman, F W M B Preijers, A P J van Dijk, J J Bax, P Roblot, P L C M van Riel, J M van Laar, D Farge. The error is regretted and a corrected version of the pdf will be published online: http://ard.bmj.com/cgi/ content/full/ard.2007.071464/DC1

Ann Rheum Dis 2008;67:280. doi:10.1136/ard.2007.071464.corr1 